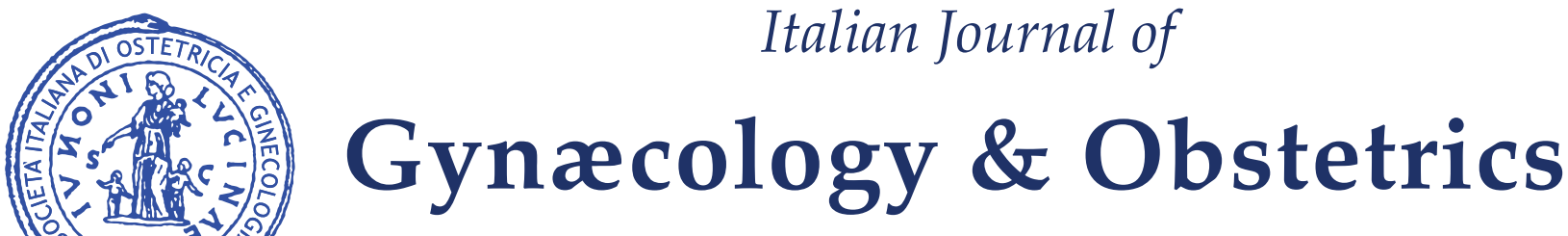

March 2021 - Vol. 33 - N. 1 - Quarterly - ISSN 2385 - 0868

\title{
Are HLA-G polymorphisms associated to recurrent pregnancy loss?
}

\author{
M. E. Vaquero ${ }^{1}$, B. Valentini ${ }^{2}$, N. Lazzarin ${ }^{2}$, A. Nuccitelli ${ }^{3}$, H. C. Valensise ${ }^{2,4}$ \\ ${ }^{1}$ Department of Biomedicine and Prevention, University of Rome Tor Vergata, Rome, Italy \\ ${ }^{2}$ Casilino University Hospital, Rome, Italy \\ ${ }^{3}$ Eurofins Genoma Group, Molecular Genetic Lab, Rome, Italy \\ ${ }^{4}$ Department of Surgery, University of Tor Vergata, Rome, Italy
}

\section{ABSTRACT}

HLA-G molecule is considered to be involved in the regulation of the maternal-foetal interface immune tolerance, thus contributing to a healthy placentation. Some polymorphisms of the gene encoding for HLA-G are suggested to affect transcription and correlate with low levels of the soluble and membrane bound HLA-G protein. Patients affected with these polymorphisms are low secreting and may have pregnancy complications. We investigated the prevalence of 3'UTR 14-base pair insertion (I)/ deletion (D) and of the single nucleotide polymorphisms (SNPs) 5'URR-725 C/G in recurrent miscarriage and healthy controls. A total of 286 couples affected with recurrent pregnancy loss (RPL) and 17 healthy couples were investigated for both polymorphisms. Couples underwent an accurate diagnostic flow chart in order to exclude causal factor of RPL and 137 couples were diagnosed as unexplained (URPL). The prevalence of the 3'UTR 14bp I/D polymorphism heterozygous was similar between URPL and control group. 3'UTR 14 bp D/D homozygotes were statistically higher in control group. Surprisingly, the prevalence of 3'UTR 14bp I/I homozygotes was similar between groups. Regarding 5'URR-725 C/G polymorphism in URPL the most prevalent haplotype was healthy homozygote $\mathrm{C} / \mathrm{C}$ in combination with $\mathrm{C} / \mathrm{G}$. No association was found between the presence of homozygotes for the low secreting 5'URR-725 G/G polymorphism and URPL. Our results indicate that the evaluation of HLA-G polymorphisms is not adequately supported in clinical practice.

\section{SOMMARIO}

La molecola HLA-G è coinvolta nella regolazione della tolleranza immunitaria dell'interfaccia materno-fetale, contribuendo così a una sana placentazione. Si ipotizza che alcuni polimorfismi del gene che codifica per HLA-G influenzino la trascrizione e siano correlati a bassi livelli della proteina HLA-G solubile legata alla membrana. I pazienti affetti da questi polimorfismi sono a bassa secrezione e possono avere complicazioni durante la gravidanza. Abbiamo studiato la prevalenza dell'inserzione/delezione di 3'UTR a 14 paia di basi e dei polimorfismi a singolo nucleotide (SNP) 5'URR-725 $\mathrm{C} / \mathrm{G}$ in aborti spontanei ricorrenti e controlli sani. Un totale di 286 coppie affette da interruzione di gravidanza ricorrente (RPL) e 17 coppie sane sono state studiate per entrambi i polimorfismi. Le coppie sono state sottoposte a un accurato diagramma di flusso diagnostico per escludere il fattore causale di RPL e 137 coppie sono state diagnosticate come inspiegabili (URPL). La prevalenza del polimorfismo I/D 3'UTR 14 paia di basi eterozigote era simile tra URPL e gruppo di controllo. 3'UTR 14 paia di basi D/D omozigoti erano statisticamente più alti nel gruppo di controllo. Sorprendentemente, la prevalenza di omozigoti 3'UTR 14 paia di basi I/ I era simile tra i gruppi. Per quanto riguarda il polimorfismo 5'URR-725 C/G in URPL, l'aplotipo più diffuso era $\mathrm{C} / \mathrm{C}$ omozigote sano in combinazione con C/G. Non è stata trovata alcuna associazione tra la presenza di omozigoti per il polimorfismo 5'URR-725 G/ G a bassa secrezione e URPL. I nostri risultati indicano che la valutazione dei polimorfismi HLA-G non è adeguatamente supportata nella pratica clinica. 
Corresponding Author: Maria Elena Vaquero

E-mail: mariaelenavaqueromartin@gmail.com

Copyright 2021

DOI: $10.36129 /$ jog. 33.01 .03
Key words:

Recurrent miscarriage; HLAG; polymorphism; 3'UTR 14 bp I/D; 5'URR SNPS.

\section{INTRODUCTION}

Sporadic miscarriage is the most frequent complication of early pregnancy. Almost 70\% of product of conception fail prior to life and most losses occur during the pre-implantation period (1). Recurrent pregnancy loss (RPL), defined as two or more spontaneous abortions prior to the $20^{\text {th }}$ week of pregnancy (ESHRE 2017), occurs in about $2 \%-5 \%$ of otherwise healthy women (2). The aetiology of this condition is often multifactorial. After ruling out traditional causes, including chromosomal anomalies, anatomical abnormalities, endocrine disturbances and clotting disorders, in about $50 \%$ of RPL cases the pathophysiology of RPL remains unexplained. Therefore, these cases may be considered as unexplained recurrent pregnancy losses (URPL) (3).

Different immunological mechanisms take place at the foetal-maternal interface ensuring the protection of the semiallogenic fetus and the maintenance of pregnancy, thus, abnormal immunologic interactions may be responsible for some cases of otherwise unexplained RPL. Decidual T lymphocytes, decidual natural killer (dNK) cells, macrophages and antigens on the extravillous trophoblast, which is the external layer of trophoblast in contact with maternal tissue, may be involved in these interactions. In particular, during early placentation, the extravillous trophoblasts, migrating into the decidua, display a unique pattern of HLA class $1 \mathrm{~b}$ molecules, with HLA-E, F and G predominating. The role of HLA-E and $F$ are still under debate. HLA-G protein is highly expressed on extravillous trophoblast and may play a role on immune modulation at that level (4).

This protein is encoded by the nonclassical HLA-G locus. There are two forms of this protein: membrane-bound and soluble (sHLA-G). The membrane bound isoforms are four: HLA-G1, HLA-G2, HLA-G3, HLA-G4 and the soluble isoforms are three: HLA-G5 (or sHLA-G1), HLA-G6 (or sHLA-G2), HLA-G7 (or sHLA-G3). Both, membrane bound and soluble HLAG, exhibit immu- nologic functions. HLA-G activates different pathways in uterine NK cells, macrophages and T cells and alters their immune function by interacting with leukocyte inhibitory receptors ILT2 (immunonoglubulin like transcript) and KIRs receptors (killer immunoglobulin-like receptors) on dNK (decidual natural killer cells) inducing the secretion of Th2 cytokines and VEGF (5), with macrophages through ILT2 and ILT4 receptors, favouring the shift toward the immunomodulatory phenotype M2 macrophages and with the ILT2 receptor on CD8+ cells, inhibiting cytotoxicity (6). HLA-G binding to ILT4 on antigen-presenting cells, suppresses T-cell proliferation, via apoptosis (7). Moreover, HLA-G is not involved in T-cell suppression exclusively with its membrane-bound form, but also with a soluble isoform in maternal serum (8-10).

Polymorphism on the gene encoding for HLA-G antigen are associated with pregnancy complication such as recurrent pregnancy loss, recurrent implantation failure, and preeclampsia (11-13), but these reports are controversial, with other studies reporting a not significant correlation between HLAG polymorphism and RPL (14-16). Among its several polymorphisms in the non-coding region of the HLA-G gene, the $14 \mathrm{bp}$ ins / del polymorphism at $33^{\prime}$ untranslated region ( $\left.3^{\prime} \mathrm{UTR}\right)$ of HLA-G gene and the single nucleotide substitution (SNP) polymorphisms HLA5'URR-725 C/G play an important role in post-transcriptional regulation of HLA-G molecule. Individuals carrying those polymorphisms have dramatically lower sHLA-G protein level in plasma and are considered low secreting haplotypes (17). Several studies on the association between HLA-G14 bp ins / del polymorphism and URPL have been performed. Low secretion of soluble HLA-G (s-HLA-G) from preimplantation embryos may be predictive of low implantation rate in in vitro fertilization, and low plasma levels of s-HLA-G may be associated with low implantation rate after in vitro fertilization and high risk of recurrent miscarriage $(18,19)$.

The role of the single nucleotide substitution polymorphism (SNPs) of the HLAG gene, substitution 
of a $C$ with $G$ in 725 position $(C / G)$, has been less studied in association with RPL This polymorphism changes the amino acid sequence of the HLA-G protein and is also responsible for the low secreting haplotypes. In a study of SNPs in the 5' URR-725 C/G of the HLA-G gene in a cohort of Hutterite couples, Ober et al. observed an increased risk of abortion in couples where both members carried the 725G allele (OR 2.8) (11).

However, no clear consensus has been reached. Because of the inconsistent results from relatively small studies with underpowered to detect the effect of these polymorphisms. Recently two metanalysis, including all relevant studies, have been conducted in order to define the influence of these polymorphisms in RPL, Wang et al. reported an association between the HLA-G14 bp insertion haplotype with RPL (OR 1.47 (1.13-1.91)) and an overall risk of RPL independent from the previous miscarriage number (17). In the other metanalysis study (20) reported the same association but only in patients with three or more RPL.

Aim of this study is to investigate the association of low secreting polymorphism 3'UTR $14 \mathrm{bp} \mathrm{I/D}$ and 5'URR-725 C/G, in couples affected with RPL compared to healthy controls. To our knowledge this is the first study that investigates both polymorphisms in both partners.

\section{MATERIALS AND METHODS}

\section{Study subjects}

In this longitudinal case-control study, subjects were recruited for investigation and treatment at the outpatient clinic for diagnosis and treatment of RPL at the University of Tor Vergata, Rome, Italy from March 2014 to March 2018. Control couples were volunteers that accepted to enter the study and signed an informed consent. All couples recruited in the study were asked for permission to get blood or oral swap samples for DNA preparation and signed an informed consent.

The study sample included 286 couples with diagnosis of RPL according to ESHRE criteria (ESHRE 2017). All women underwent diagnostic flow chart for RPL and clinical features of control group are reported in table I:

- BMI;

- assessment of primary or secondary RPL;

- number of abortions;
Table I. Clinical features of RPL population.

\begin{tabular}{lc}
\hline & RPL population \\
\hline Mean Age & 37 \\
\hline Mean BMI & 23 \\
\hline Mean Nr. of abortions & 3 \\
\hline Mean Week of abortion & 7 \\
\hline Primary RPL & $75.70 \%$ \\
\hline Secondary RPL & $24.30 \%$ \\
\hline
\end{tabular}

- average Week of abortion of RPL;

- karyotype of issue of conception (when available);

- karyotype of both partners;

- TSH, fT3, fT4;

- Anti-thyroglobulin antibodies, Anti-thyroid peroxidase antibodies;

- prothrombin 20210 mutation (factor II mutation);

- factor V Leiden mutation;

- protein S and protein C, ATIII;

- Lupus Anticoagulant antibodies (according to Bradford Hill recommendations);

- anticardiolipin antibodies (according to Bradford Hill recommendations);

- anti-beta-2-glycoproteins antibodies (according to Bradford Hill recommendations);

- ENA, ANA, DsDNA, antitransglutaminase ab;

- genotyping of HLA-G for haplotypes.

After the full evaluation of the 286 couples, according to the diagnostic flow chart, 149 couples were multifactorial RPL and 137 couples resulted as unexplained (URPL). Clinical features of RPL patients are summarized in table I.

\section{Control population}

A total of 17 couples were recruited to this study. The inclusion criteria were:

- no abortions;

- 2 or more live births;

- no obstetrical complications;

- age $<65$ years.

Clinical features controls are reported in table II.

\section{DNA isolation}

DNA was extracted from $200 \mathrm{ml}$ of peripheral blood or oral swap in EDTA according to the Qiagen DNA mini kit (Sambrook et al., 2000). PCR amplification of each region of interest was performed using the outer oligonucleotide primers. Mutation analysis was carried out by direct sequencing of PCR products 
Table II. Clinical features of control population.

\begin{tabular}{lc}
\hline \multicolumn{2}{c}{ Control population } \\
\hline Age & 48 \\
\hline Mean BMI & 25 \\
\hline Mean nr. of abortion & 0 \\
\hline Mean nr. of pregnancies & 2 \\
\hline Obstetric complication & None \\
\hline
\end{tabular}

using Big Dye Terminator Cycle Sequencing Ready Reaction Kit (Applied Biosystems, USA), according to the protocol provided by the manufacturer.

\section{Amplification and sequencing of HLAG-gene}

For sequence analysis, $20 \mathrm{ng}$ of purified PCR products were sequenced by direct cycle sequencing using-fluorescent-labelled dideoxy terminators (Big Dye Terminator Cycle Sequencing Ready Reaction Kit; Applied Biosystems), according to the manufacturer's protocol. The reaction conditions were as follows: 25 PCR cycles, a denaturation step of $10 \mathrm{~s}$ at $96{ }^{\circ} \mathrm{C}$, annealing for $5 \mathrm{~s}$ at $50{ }^{\circ} \mathrm{C}$ and extension for $4 \mathrm{~min}$ at $60^{\circ} \mathrm{C}$. Sequencing products were then purified using Centre-Sep columns (Princeton Separation) for unincorporated dye terminator removal, according to the protocol provided by the manufacturer. Five microliters of each Centri-Sep ${ }^{\circledR}$ purified product were then added to $15 \mathrm{ml}$ of $\mathrm{Hi}-\mathrm{Di}$ Formamide (Applied Biosystems), heat-denatured at $90{ }^{\circ} \mathrm{C}$ for 4 min and run on ABI Prism ${ }^{\circledR} 310$ automated DNA sequencer (Applied Biosystems). The sequences obtained were then compared with the wild type controls using Sequence Navigator ${ }^{\circledR}$ Software (Applied Biosystems) for mutation analysis. The minisequencing reaction was performed, starting from $10 \mathrm{ng}$ of the same purified PCR product subjected to sequence analysis, using ABI Prism ${ }^{\circledR}$ SnaPshot Multiplex Kit (Applied Biosystems). The reaction volume was $10 \mathrm{ml}$, including $5 \mathrm{ml}$ of Ready Reaction Premix and 10 pmol of each minisequencing primer. The reaction conditions were as follows: 25 PCR cycles, denaturation step of $10 \mathrm{~s}$ at $96^{\circ} \mathrm{C}$, annealing for $10 \mathrm{~s}$ at $50^{\circ} \mathrm{C}$ and extension for $30 \mathrm{~s}$ at $60^{\circ} \mathrm{C}$.

In the minisequencing technique, a primer extension reaction is performed, starting from a specific primer that is designed to anneal directly adjacent to the mutation site, by the incorporation of a single fluorescent dideoxynucleotide (ddNTP), which is complementary to the variant base in the template. Since the primer is designed to anneal directly adjacent to the variant base of interest, and the reaction mix does not include dNTP, incorporation occurs only at a single site. This process is repeated in successive rounds of extension and termination to generate the fluorescently labelled fragment for analysis. After the primer extension reaction, $1 \mathrm{ml}$ of minisequencing product was mixed with $15 \mathrm{ml}$ of $\mathrm{Hi}-\mathrm{Di}$ Formamide and denatured for $4 \mathrm{~min}$ at $90{ }^{\circ} \mathrm{C}$. The samples were then resolved and detected by $15 \mathrm{~min}$ (per blastomere) of capillary electrophoresis on automatic DNA sequencer ABI Prism ${ }^{\circledR} 310$, using POP$4^{\circledR}$ polymer and $47 \mathrm{~cm} \times 50 \mathrm{~mm}$ capillaries. Thus, the mutation sites could reliably be differentiated among homozygotes wild types, homozygotes mutants or heterozygotes, by the dye-labelled ddNTP incorporated. To reveal the electrophoresis data, the peak signal was analysed with GeneScan ${ }^{\circledR}$ Analysis Software (Applied Biosystems); the dye colour of the fragment was used to identify the nucleotide of interest. For the minisequencing technique, colour was assigned to individual ddNTP as follows: green/A, black/C, blue/G, red/T. For sequencing, instead colours were assigned as follows: green/A, black/G, blue/C, red/T. The minisequencing reaction produces one (homo-zygote) or two (heterozygote) peaks depending on the genotype at this locus.

\section{PCR amplification and minisequencing primers design}

The PCR strategy consisted of initial multiplex external amplification followed by nested PCR, specific for each region involving mutations. After cell lysis and neutralization, $1.5 \mathrm{mmol} / 1 \mathrm{MgCl}_{2}$, $200 \mathrm{mmol} / 1$ of each dNTP (Roche Diagnostic, Italy), 2.5 IU AmpliTaqPolymerase (Applied Biosystems), $10 \mathrm{pmol}$ of each outer primer, were added to each tube, for a total volume of $50 \mathrm{ml}$. The first round of PCR involved a $96^{\circ} \mathrm{C}$ denaturation temperature in the first 10 cycles as a means to reduce ADO (21), followed by a subsequent denaturation temperature of $94{ }^{\circ} \mathrm{C}$ in 25 remaining cycles. Each round of PCR was preceded by an initial 4 min denaturation step at $94{ }^{\circ} \mathrm{C}$ and followed by a final extension step of $10 \mathrm{~min}$ at $72{ }^{\circ} \mathrm{C}$. The extension temperature depended on the specific primers used. PCR positive heterozygous controls containing a single lymphocyte (two control cells for each genotype) isolated from carriers were also added.

For the second round of DNA amplification, $2 \mathrm{ml}$ of the primary PCR reaction product were added to another tube containing $5 \mathrm{ml}$ of 10QPCR Buffer II (500 $\mathrm{mmol} / 1 \mathrm{KCl}, 100 \mathrm{mmol} / 1$ Tris HCl, $\mathrm{pH}$ 8.3; Applied Biosystems), $1.5 \mathrm{mmol} / 1 \mathrm{MgCl}_{2}, 200 \mathrm{mmol} / 1$ of each 
dNTP (Roche Diagnostic), 2.5 IU AmpliTaqPolymerase (Applied Biosystems), 10 pmol of each inner primer, in a total volume of $50 \mathrm{ml}$, and the tubes were cycled as above on a GeneAmpa PCR System 9700 (Applied Biosystems).

To monitor successful amplification, $5 \mathrm{ml}$ of each PCR product was subjected to electrophoresis for $5 \mathrm{~min}$ at $150 \mathrm{~V}$ on $2 \%$ agarose gel in 1QTris \pm borate/ EDTA buffer stained with $0.5 \mathrm{mg} / \mathrm{ml}$ ethidium bromide.

To avoid participation in the subsequent primer-extension reaction, primers and unincorporated dNTP were removed from PCR products by performing Microcon 100 (Amicon, USA) purification, according to the manufacturer's protocol.

Mutation analysis was carried out only on positively amplified blastomeres, using two different techniques simultaneously: sequence analysis and minisequencing.

After mutation detection, minisequencing primers were designed for each mutation investigated with the aid of Primer Express ${ }^{\circledR}$ software (Applied Biosystems) and initially tested on sequenced PCR products. Desalted primers were purchased from MWG-Biotech (Germany). The guidelines for primer design included the following parameters:

1. Design primers 18 nucleotides in length or greater with melting temperatures of $\mathrm{b} 45^{\circ} \mathrm{C}$;

2. check primers for possible extendable hairpin structures and for extendable dimer formation between primers;

3. high performance liquid chromatography purification of primers is recommended for oligonucleotides longer than 30 nucleotides;

4. use primers that are complementary to the negative $( \pm)$ DNA strand, if the positive (+) DNA strand is difficult to assay;

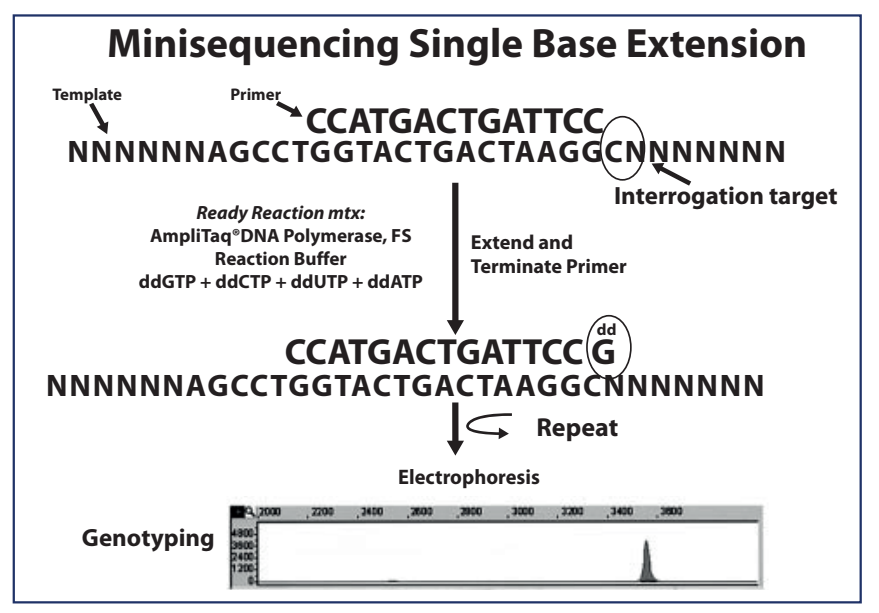

Figure 1. Dna extraction and amplification.
5. in multiplex reaction, primers must differ significantly in length so that overlap between the final products will be avoided.

A difference of $4 \pm 6$ nucleotides between primer lengths is recommended. The length of a primer can be modified by the addition of non-homologous polynucleotides at the 5 \& end. Poly (dT), poly (dA), poly $(\mathrm{dC})$ and poly (dGACT) are $5^{\prime}$ non-homologous tails, which are predicted to have minimal secondary structures. This procedure is summarized in figure 1.

\section{Statistical analysis}

Full data were entered in an Excel sheet (Microsoft, Redmond, Washington - USA) and they were analysed by a statistics pack for social sciences Windows, version 1.5 (SPSS, Chicago, Illinois, USA). The interaction between the presence/absence of a variables at any specific group membership was tested using a Fisher's exact test. OddsRatio $(\mathrm{OR})$, a measure of association between the two variables and confidence interval $(\mathrm{CI})$, asymptotic confidence interval for the odds ratio were reported. Statistically meaningful are the values with $\mathrm{p}<0.05$.

All charts were designed by Excel (Microsoft, Redmond, Washington, USA).

\section{RESULTS}

Patients affected with RPL underwent a very extensive diagnostic flow chart and more investigations were performed beyond the traditional factors of RM (genetic, anatomic and aPL syndrome) since they were included in a research program. The prevalence of different aetiologies is summarized in figure 2 .

In particular 21 out of $286(7 \%)$ were affected with aPL syndrome, 81 out of $286(28 \%)$ had thyroid abnormalities, 5 out of $286(2 \%)$ had uterine Mullerian anomalies, 2 out of $286(1 \%)$ had chromosomal abnormalities, 16 out of $286(6 \%)$ had hereditary thrombophilia, 24 out of $286(8 \%)$ had associated causes of RM. No causal factor of RPL was found in 137 and they were classified as idiopathic or unexplained URPL.

The statistical analysis in the prevalence of HLAG polymorphisms was performed in 137 unexplained recurrent pregnancy loss couples (URPL), compared to 17 healthy controls. 


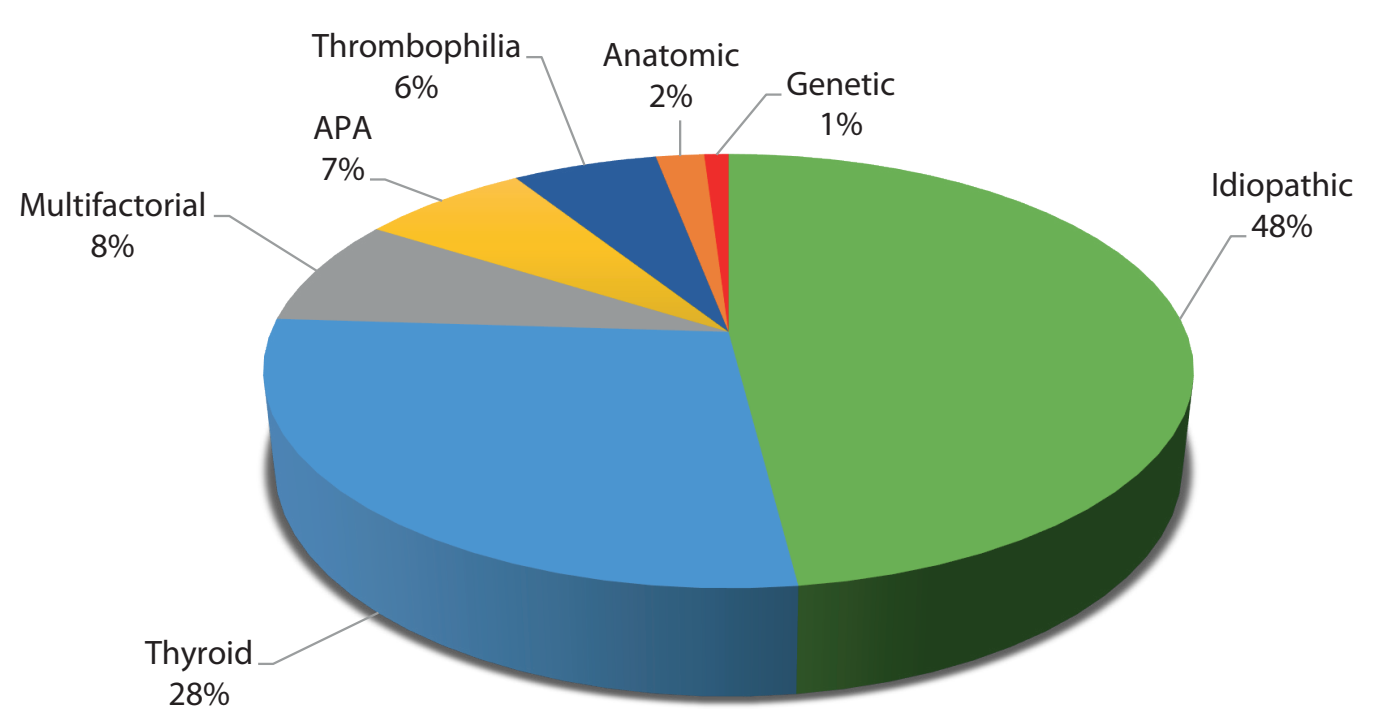

-Idiopathic $\square$ Thyroid $\square$ Multifactorial $\square$ APA $\square$ Thrombophilia $\square$ Anatomic $\square$ Genetic

Figure 2. Aetiologies of RPL in 286 selected patients after diagnostic flow chart.

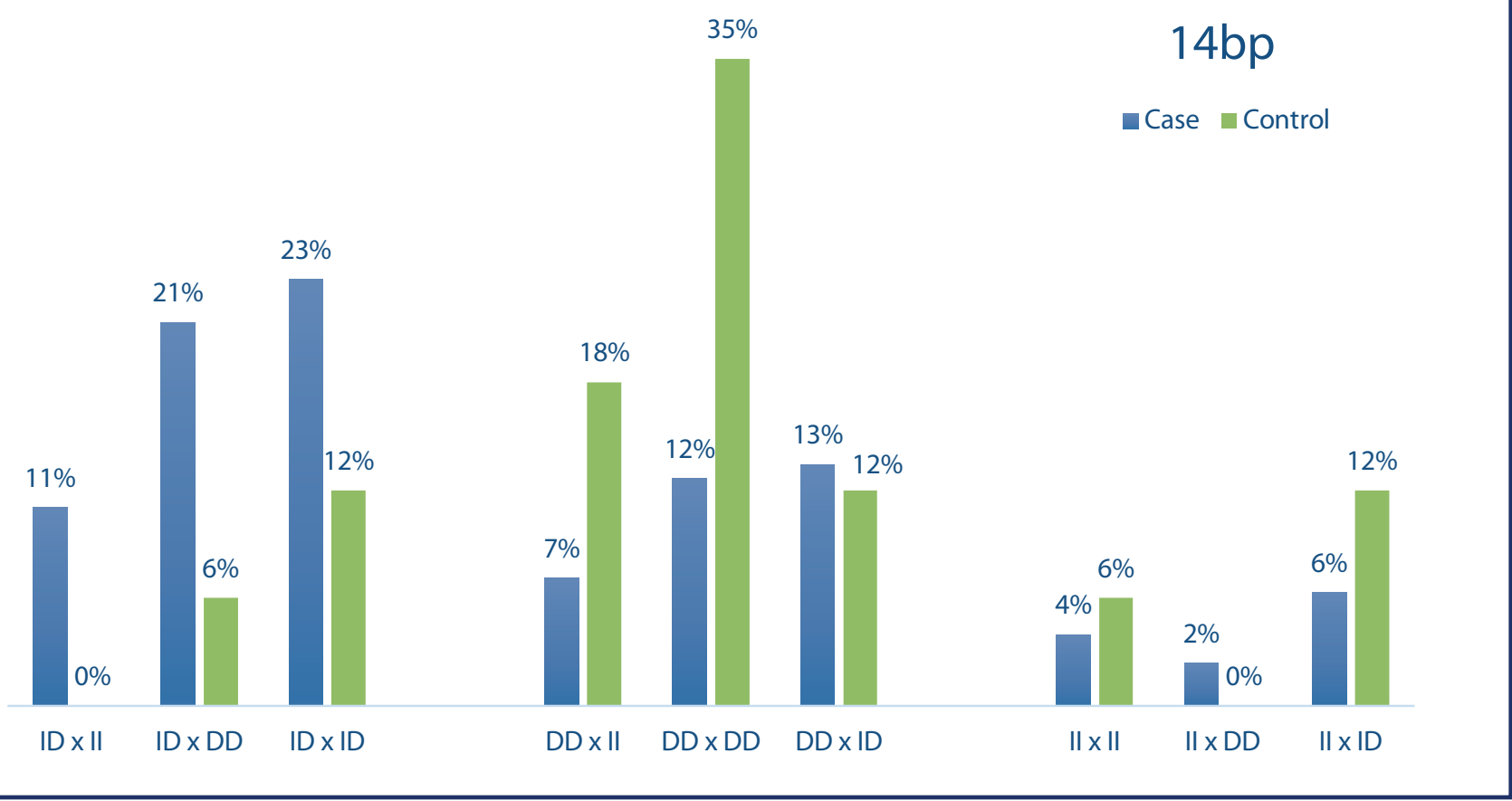

Figure 3. Comparison of 14bp I/D haplotypes between URPL couples vs control group.

\section{3'UTR $14 b p$}

In URPL population, the low secreting haplotype of 3' UTR 14bp (I/D) has the highest incidence (101 partners out of 274 total subjects in case group, 37\%). In control population, the normal secreting haplotype of 3'UTR 14bp (D/D) was the most prevalent haplotype (18 partners out of 34 total subjects in control group, 53\%) (table III).

In URPL population, most of the couples have at least one low secreting haplotype: 31 couples $(23 \%)$ have the association I/D $\times \mathrm{I} / \mathrm{D}$ and 28 couples $(20 \%)$ have the association I/D x D/D. Nonetheless, the prevalence of $14 \mathrm{bp}$ heterozygous combi- 
nations in URPL, compared to healthy group, did not reach statistical significance.

In control population, 6 couples out of $17(35 \%)$ were homozygous for the normal secreting association $\mathrm{D} / \mathrm{D} \times \mathrm{D} / \mathrm{D}$, compare to $12 \%$ (16 out of 137) in URPL couples. We found a statistically significant higher prevalence of homozygous combination $\mathrm{D} / \mathrm{D} \times \mathrm{D} / \mathrm{D}$ in couples with normal pregnancy outcome compare to URPL ( $\mathrm{p}=0.018 ; \mathrm{OR}=0.242)($ table III, figure 3$)$.

\section{5'UTR 725}

Normal secreting haplotypes combination CC x CC was the most prevalent both in control (29\%) and URPL ( $53 \%$ ) but do not reach statistical significance. A significantly higher prevalence of the $\mathrm{C} / \mathrm{C} \times \mathrm{C} / \mathrm{G}$ combination was found in healthy controls (29\%) compare

Table III. Prevalence of 14 bp I/D haplotypes in URPL couples vs controls.

\begin{tabular}{|c|c|c|c|c|}
\hline $\begin{array}{l}\text { Variable } \\
\text { (14 bp) }\end{array}$ & $\begin{array}{l}\text { Patients, } \\
\text { n (\%) }\end{array}$ & $\begin{array}{l}\text { Controls, } \\
\text { n (\%) }\end{array}$ & p-value & OR [Cl] \\
\hline ID x II & $15(11 \%)$ & $0(0 \%)$ & Ns & - \\
\hline ID $\times$ DD & $28(20 \%)$ & $1(6 \%)$ & Ns & - \\
\hline ID $\times$ ID & 31 (23\%) & $2(12 \%)$ & Ns & - \\
\hline DD $x \|$ & $10(7 \%)$ & $3(18 \%)$ & Ns & - \\
\hline $\mathrm{DD} \times \mathrm{DD}$ & $16(12 \%)$ & $6(35 \%)$ & $0.018^{*}$ & $\begin{array}{l}0.242 \\
{[0.079-0.745]}\end{array}$ \\
\hline DD x ID & $18(13 \%)$ & $2(12 \%)$ & Ns & - \\
\hline$\|x\|$ & $6(4 \%)$ & $1(6 \%)$ & Ns & - \\
\hline$I I \times D D$ & $4(3 \%)$ & $0(0 \%)$ & Ns & - \\
\hline$\| \times \mid D$ & $9(7 \%)$ & $2(12 \%)$ & Ns & - \\
\hline
\end{tabular}

to URPL $(10 \%)(\mathrm{p}=0.039 ; \mathrm{OR}=0.273)$. Surprisingly, we do not find any difference in the prevalence of the low secreting combination GG x GG between URPL $(1 \%)$ and controls $(6 \%)(\mathrm{Ns})$ (table IV, figure 4$)$.

\section{CONCLUSIONS AND DISCUSSION}

For more than two decade the HLAG molecule has been considered as an immune regulator towards tolerance of the semi-allogenic embryo $(4,14,22,23)$. An elevated HLA-G expression is also involved in the mechanisms to evade immune surveillance in viral infections (24), tumours immune escape and as a marker in transplantation outcome (25). Moreover, HLA-G has been detected in seminal plasma, and paternal s-HLAG seems to play a role in the implantation process of the blastocyst trough the inhibition of CD4 T cells proliferation and the induction of T Regs at the endometrial level (26). An association between low levels of s-HLAG in maternal plasma and the development of preeclampsia has also been reported (9, 27). As above mentioned both polymorphisms of the 3' UTR untranslated region $14 \mathrm{bp}$ and single nucleotide substitution of the $5^{\prime}$ URR- $725 \mathrm{C} / \mathrm{G}$ affect the expression and function of s-HLAG, and correlate with pregnancy complications such as preeclampsia (27) and recurrent pregnancy loss $(14,22)$.

In the present study the prevalence of the HLAG gene polymorphism was evaluated in couples with URPL and in controls. We analysed the presence or absence of the $14 \mathrm{bp}$ segment at the $3^{\prime}$ UTR region, the single nucleotide substitution $\mathrm{C} / \mathrm{G}$ at the 5' URR-725 segment of the gene, and the haplotype distributions among couples with URPL and controls. To our knowledge, this is the first study that evaluates both polymorphisms in both partners, and not only in the female partner.

Our data fail to demonstrate a clear association between URPL and HLAG gene polymorphisms. Analysing the 14bp polymorphism of HLAG at 3' UTR region, no differences were found in the prevalence of the low secreting haplotypes between URPL and normal control couples. Interestingly, the prevalence of the normal secreting haplotypes (D/D X D / D) was higher in healthy couples suggesting a possible positive effect on trophoblast invasion (figure 3). Basing on this observation, it could be speculated that the presence of low secreting haplotypes does not influence implantation process whereas the normal secreting haplotypes could have a protective role, improving pregnancy outcomes. Conversely, the evaluation of the 5' URR - 725 SNP polymorphisms in our series provided conflicting results. No significant differences were found between URPL patients and normal control couples. In particular, the prevalence of the low secreting haplotypes was similar

Table IV. Prevalence of - 725 C/G haplotypes in URPL couples vs controls.

\begin{tabular}{|c|c|c|c|c|}
\hline $\begin{array}{l}\text { Variable } \\
\text { (14 bp) }\end{array}$ & $\begin{array}{l}\text { Patients, } \\
\text { n (\%) }\end{array}$ & $\begin{array}{l}\text { Controls, } \\
\text { n (\%) }\end{array}$ & $p$-value & OR [Cl] \\
\hline $\mathrm{CC} \times \mathrm{CC}$ & 73 (53\%) & $5(29 \%)$ & ns & \\
\hline$C C \times G G$ & $5(4 \%)$ & $1(6 \%)$ & ns & \\
\hline$C C \times C G$ & 14 (10\%) & 5 (29\%) & $0.039^{*}$ & $\begin{array}{l}0.273 \\
{[0.084-0.890]}\end{array}$ \\
\hline $\mathrm{GG} \times \mathrm{CC}$ & $4(3 \%)$ & $0(0 \%)$ & ns & \\
\hline $\mathrm{GG} \times \mathrm{GG}$ & $0(0 \%)$ & $1(6 \%)$ & ns & \\
\hline $\mathrm{GG} \times \mathrm{GC}$ & $2(1 \%)$ & $1(6 \%)$ & ns & \\
\hline$C G \times C C$ & 22 (16\%) & $3(18 \%)$ & ns & \\
\hline $\mathrm{CG} \times \mathrm{GG}$ & $4(3 \%)$ & $0(0 \%)$ & ns & \\
\hline$C G \times C G$ & $13(9 \%)$ & $1(6 \%)$ & ns & \\
\hline
\end{tabular}




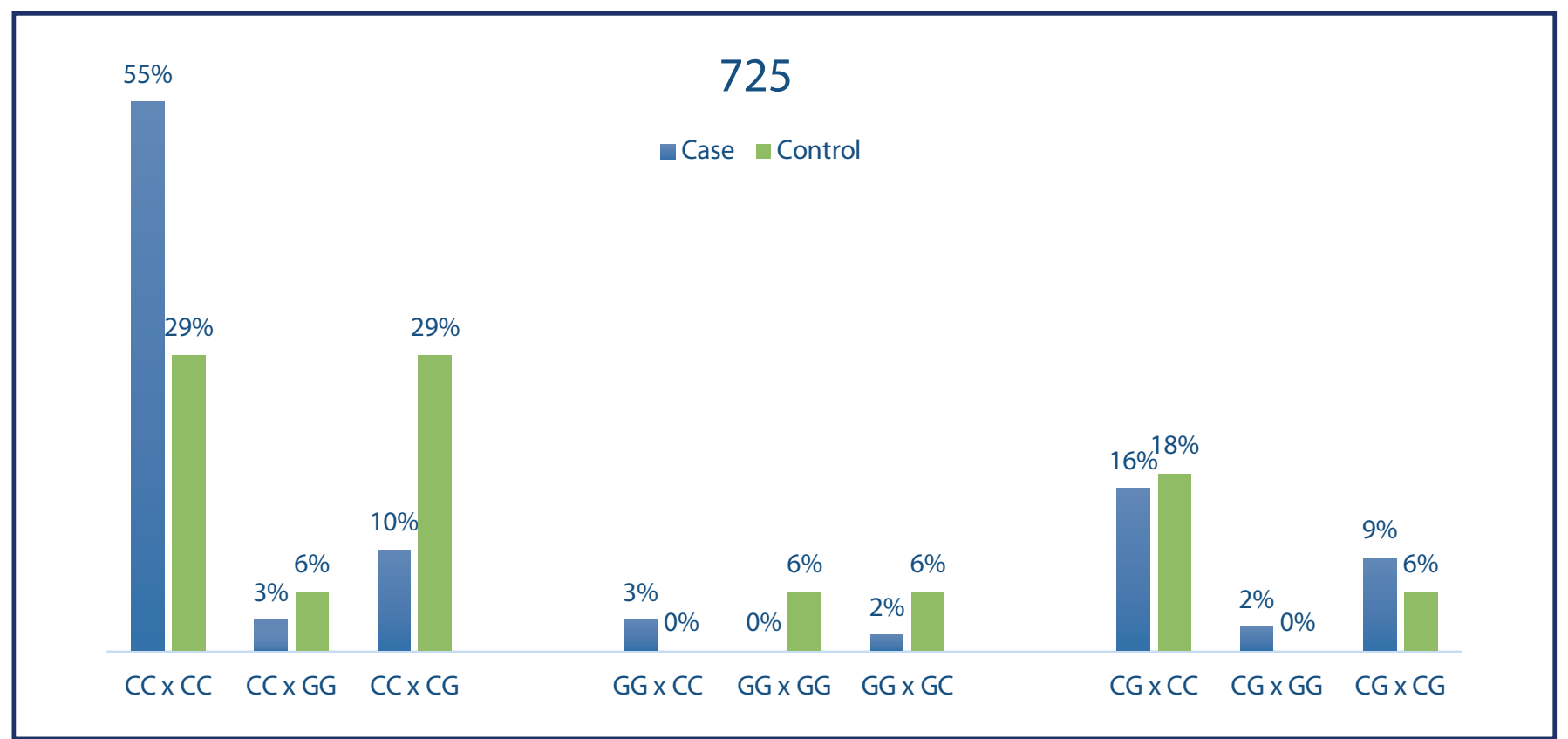

Figure 4. Comparison of $-725 \mathrm{C} / \mathrm{G}$ haplotypes between URPL couples vs control group.

in both groups and, surprisingly, in our population the normal secretive haplotype $(\mathrm{C} / \mathrm{C})$ was the most prevalent. Moreover, we found a slightly increased prevalence of the CC $\times$ CG polymorphism in control group. These data, although in contrast with previously reported evidence, seem to suggest that the $5^{\prime}$ URR - 725 SNP polymorphisms should not be considered among causal factors of RPL. This discrepancy with the previous papers, may be due to the fact in most studies that $5^{\prime}$ URR 725 SNP polymorphism evaluation was performed only in the female partner. Nonetheless, the paper by Coulam and Roussev (29) reported a higher incidence of G/G haplotype in RPL couples. These conflicting data suggest that further well designed studies including a higher number of cases and controls, are needed to ascertain the role of $5^{\prime} \mathrm{URR} 725$ polymorphism in RPL.

Another confounding factor in the role of HLAG polymorphisms may be due to the multifactorial aetiology of RPL. Some studies did not exclude other aetiologies of their population and this may represent a bias (30). For this reason, our patients underwent a very extensive diagnostic flow chart in order to exclude traditional factors of RPL. Patients included in our studies had other associated aetiologies in $52 \%$ and were URPL in $48 \%$ of cases. The statistical comparison of HLAG polymorphisms prevalence was, therefore, performed between 137 URPL couples and controls. An important drawback of our study is due to the small number of patients of control group. Even though the prevalence of HLAG haplotypes found in our control patients was similar to the one reported in other papers with more control patients (19).

In conclusion, this is the first report to perform a comprehensive analysis of 3' URT $14 \mathrm{bp}$ I/D polymorphisms and 5' URR 725 C/G SNP in both partners in a population on URPL. Our study does not find any association neither with heterozygous 14 bp polymorphism and URPL, nor with homozygous that is supposed have impaired levels of sHLAG. The association between 5' URR 725G heterozygous polymorphism and URPL, provides conflicting results, since the low secreting association CC x CG was more prevalent in control group. The role of HLAG in the pathogenesis of RPL is challenged. In basic research, deeper analysis is necessary on the role of immune cells, cytokines and receptor interaction and molecules at the maternal-foetal interface. In clinical studies, well-designed and powered trials are needed to examine HLA alleles, polymorphism and sHLAG protein level in couples experiencing RPL. Actually, according to the ESHRE guidelines and to our data, the evaluation of HLAG polymorphisms is not adequately supported in clinical practice.

\section{CONFLICT OF INTERESTS}

The authors declare that they have no conflict of interests. 


\section{REFERENCES}

1. Ford HB, Schust DJ. Recurrent pregnancy loss: etiology, diagnosis and therapy. Rev Obstet Gynecol 2009;76(2).

2. Jauniaux E, Farquharson RJ, Christiansen OB, Exalto N. Evidence based guidelines for the investigation and medical treatment of recurrent miscarriage. Human Reprod 2006;21:2216.

3. Practice Committee of the American Society for Reproductive Medecine. Definition of infertility and recurrent pregnancy loss: a committee opinion. Fertil Steril 2020.

4. Dahl M, Djurisic S, Hviid, TVF. The Many Faces of Human Leukocyte Antigen-G: Relevance to the Fate of Pregnancy. J Immunol Res 2014:1-11.

5. Svendsen S, Hantash B, Zhao L, et al. The expression and functional activity of membrane-bound human leukocyte antigen-G1 are influenced by the 3'-untranslated region. Human Immunol 2013;74(7):818-27.

6. Shakhawat A, Shaikly V, Elzatma E, Mavrakos E, Jabeen A, Fernández N. Interaction between HLA-G and monocyte/macrophages in human pregnancy. J Repr Immunol 2010;85(1):40-6.

7. Naji A, Le Rond S, Durrbach A, et al. CD3+CD4low and CD3+CD8 low are induced by HLA-G: novel human peripheral blood suppressor T-cell subsets involved in transplant acceptance. Blood 2007;110(12):3936-48.

8. Fournel S, Aguerre-Girr M, Huc X, et al. Cutting Edge: Soluble HLA-G1 Triggers CD95/ CD95 Ligand-Mediated Apoptosis in Activated CD8+ Cells by Interacting with CD8. J Immunol 2000;164(12):6100-4.

9. Hunt J, Petroff M, Morales P, Sedlmayr P, Geraghty D, Ober C. HLA-G in reproduction: studies on the maternal-fetal interface. Human Immunol 2000;61(11):1113-7.

10. Hunt J, Morales P, Pace J, Fazleabas A, Langat D. A Commentary on Gestational Programming and Functions of HLA-G in Pregnancy. Placenta 2007;28:S57-63.

11. Ober C, Aldrich C, Rosinsky B, et al. HLA-G1 protein expression is not essential for fetal survival. Placenta 1998;19(2-3):127-32.

12. Hviid T, Larsen L, Hoegh A, Bzorek M. HLA-G Expression in Placenta in Relation to HLA-G Genotype and Polymorphisms. Am J Reprod Immunol 2004;52(3):212-7.

13. Christiansen OB, Kolte AM, Dahl M, et al. Maternal homozygocity for a 14 base pair insertion in exon 8 of the HLA-G gene and carriage of HLA class II alleles restricting $\mathrm{HY}$ immunity predispose to unexplained secondary recurrent miscarriage and low birth weight in children born to these patients. Human Immunol 2021;73(7):699-705.

14. Vargas R, Sarturi $P$, Mattar $S$, et al. Association of HLA-G alleles and 3' UTR 14 bp haplotypes with recurrent miscarriage in Brazilian couples. Human Immunol 2011;72(6):479-85.

15. Yan WH, Fan LA, Yang JQ, Xu LD, Ge Y, Yao FJ. HLA-G polymorphism in a Chinese Han population with recurrent spontaneous abortion. In J Immunogen 2006;33(1):55-8.

16. Sipak-Szmigiel O, Cybulski C, Lubiński J, Ronin-Walknowska E. HLA-G polymorphism in a Polish population and reproductive failure. Tissue Antigens 2007;0(0).

17. Hviid TVF, Christiansen OB. Linkage Disequilibrium Between Human Leukocyte Antigen (HLA) Class II and HLA-G-Possible Implications for Human Reproduction and Autoimmune Disease. Human Immunol 2005;66(6):688-99.

18. Wang $X$, Jiang W, Zhang D. Association of 14bp insertion/deletion polymorphism of HLA-G gene with unexplained recurrent spontaneous abortion: a meta-analysis. Tissue Antigens 20013;81(2):108-15.

19. Hunt J, Petroff M, McIntire R, Ober C. HLA-G and immune tolerance in pregnancy. The FASEB J 2005;19(7):681-93.

20. Dahl M, Hviid T. Human leucocyte antigen class $\mathrm{Ib}$ molecules in pregnancy success and early pregnancy loss. Human Reprod Update 2011;18(1):92-109.

21. Fan W, Li S, Huang Z, Chen Q. Relationship between HLA-G polymorphism and susceptibility to recurrent miscarriage: A meta-analysis of non-family-based studies. J Assisted Reprod Gen 2013;31(2);173-84.

22. Ray P, Handyside A. Increasing the denaturation temperature during the first cycles of amplification reduced allele dropout from single cells for preimplantation genetic diagnosis. Mol Human Reprod 1996;2(3):213-8.

23. Kolte A, Steffensen R, Nielsen H, Hviid T, Christiansen O. Study of the structure and impact of human leukocyte antigen (HLA)-G-A, HLA-G-B, and HLA-G-DRB1 haplotypes in families with recurrent miscarriage. Human Immunol 2010;71(5):482-8.

24. Vento-Tormo R, Efremova M, Botting R, et al. Single-cell reconstruction of the early maternal-fetal interface in humans. Nature 2018;563(7731):347-53. 
25. Lozano J, González R, Luque J, Frias M, Rivero A, Peña J. CD8+HLA-G+ Regulatory T Cells Are Expanded in HIV-1-Infected Patients. Viral Immunol 2009;22(6):463-5.

26. Brugière $\mathrm{O}$, Thabut $\mathrm{G}$, Pretolani $\mathrm{M}$, et al. Immunohistochemical Study of HLA-G Expression in Lung Transplant Recipients. Am J Transplan 2009;9(6):1427-38.

27. Larsen $\mathrm{MH}$, Bzorek $\mathrm{M}$, Pass $\mathrm{M}$, et al. Human Leucocyte antigen- $G$ in the male reproductive system and seminal plasma. Mol Human Reprod 2011;17(12):727-38.

28. Larsen M, Hylenius S, Andersen A, Hviid T. The 3 '-untranslated region of the HLA-G gene in re- lation to pre-eclampsia: revisited. Tissue Antigens 2010;75(3):253-61.

29. Favier B, LeMaoult J, Lesport E, Carosella E. ILT2/HLA-G interaction impairs NK-cell functions through the inhibition of the late but not the early events of the NK-cell activating synapse. FASEB J 2010;24(3):689-99.

30. Roussev RG, Coulam CB. HLA-G and its role in implantation (review). J Assisted Reprod and Gen 2007;24(7):288-95.

31. Amodio G, Canti V, Maggio L, et al. Association of genetic variants of 3'UTR of HLA-G with recurrent pregnancy loss. Human Immunol 2016;(77):836-91. 